\title{
HER-2/NEU EXPRESSION IN STOMACH AND GASTRO-OESOPHAGEAL JUNCTION CARCINOMA IN ENDOSCOPIC BIOPSY SPECIMENS
}

\author{
Surinder Kumar Atri ${ }^{1}$, Virender Mohan Rana ${ }^{2}$, Vijant Singh Chandial ${ }^{3}$ \\ ${ }_{1}^{1}$ Associate Professor, Department of Pathology, Government Medical College, Jammu, Jammu and Kashmir. \\ 2Demonstrator, Department of Pathology, Government Medical College, Jammu, Jammu and Kashmir. \\ ${ }^{3}$ Associate Professor, Department of Medicine, Government Medical College, Jammu, Jammu and Kashmir.
}

\begin{abstract}
BACKGROUND

Prognosis of patients with advanced inoperable carcinoma of stomach and gastro-oesophageal junction remains dismal with palliative chemotherapy. In spite of extensive efforts, the five-year survival rate of these patients worldwide is $20 \%$. The main problem with chemotherapy is its toxicity and thus the management of these patients is very complex. These patients also have associated comorbidities. Therefore, there is a need to understand the molecular biology of these malignancies and develop personalised, specialised and molecular targeted therapy. Hence, we planned this study to evaluate the expression of HER-2/neu in carcinoma of stomach and gastro-oesophageal junction.
\end{abstract}

\section{MATERIALS AND METHODS}

This was an observational study from January 2010 to December 2016 wherein all cases of carcinoma of stomach and gastrooesophageal junction were retrieved and reviewed. Immunohistochemistry for HER-2/neu protein was done. Statistical analysis was done using SPSS 10.0 windows student version \{SPSS Inc., 233 South Wacker Drive, 11 th Floor, Chicago, IL 60606-6412\}.

\section{RESULTS}

The age of patients varied from 34 to 72 years and mean age was 58.5 years. The common clinical presentation was dyspepsia and regurgitation (82.4\%). Of total 85 cases, the grade of HER-2/neu expression was as follows: 0 in $65(76.47 \%)$ cases, $1+$ in 2 (2.3\%) cases, $2+$ (equivocal) in $4(4.70 \%)$ cases and $3+$ in $14(16.47 \%)$ cases.

\section{CONCLUSION}

Assessment of HER-2/neu gene amplification by FISH technique and HER-2/neu protein overexpression by immunohistochemistry should be done in all patients with gastric and gastro-oesophageal carcinoma especially inoperable cases so that these patients are treated with molecularly targeted therapy.

\section{KEYWORDS}

Carcinoma, Stomach, Gastro-oesophageal Junction, HER-2/neu and Immunohistochemistry.

HOW TO CITE THIS ARTICLE: Atri SK, Rana VM, Chandial VS. HER-2/neu expression in stomach and gastro-oesophageal junction carcinoma in endoscopic biopsy specimens. J. Evolution Med. Dent. Sci. 2017;6(88):6123-6126, DOI: 10.14260/jemds/2017/1330

\section{BACKGROUND}

Stomach carcinoma is the fourth most common cancer in incidence and second most common cause of cancer deaths. ${ }^{1}$ The annual incidence of carcinoma of stomach and gastrooesophageal junction is 1.4 million cases, and annual deaths because of these malignancies are 1.1 million. Therefore, carcinoma of stomach and gastro-oesophageal junction poses a major global health problem. ${ }^{2}$ In India, the incidence of gastric carcinoma is higher in the southern and north-eastern states with Mizoram recording an age-adjusted rate of 50.6 and 23.3 for men and women respectively. 3,4 A recent assessment of 556,400 deaths due to cancer in India in 2010 based on a nationally representative survey found that stomach cancer with a mortality rate of $12.6 \%$ is the second most common fatal cancer. ${ }^{5}$

'Financial or Other Competing Interest': None.

Submission 10-10-2017, Peer Review 28-10-2017,

Acceptance 31-10-2017, Published 06-11-2017.

Corresponding Author:

Dr. Surinder Kumar Atri,

Associate Professor,

House No. 24, Lane 51,

Behind Sunny Farms, Greater Kailash Post Office,

Gangyal, Jammu, Jammu and Kashmir.

E-mail: surinderkumaratri@gmail.com

DOI: $10.14260 /$ jemds/2017/1330

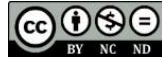

The incidence of carcinoma stomach has declined in the recent past whereas the incidence of carcinoma gastrooesophageal junction has risen dramatically. ${ }^{2}$ Despite advances in the treatment and management of carcinoma stomach, 5-year survival rate remains around $20 \%$ in most parts of the world except Japan where 5-year survival rate is around $60 \%$ due to screening programmes, staging systems and treatment. 6 The poor survival rates in carcinoma of the stomach and gastro-oesophageal junction are because most of the patients present in advanced stages at the time of diagnosis. These patients present in advanced stage because their clinical presentation is initially nonspecific and by the time they are diagnosed, they present with local and metastatic spread. If the disease can be diagnosed at earlier stages through effective screening programmes and rapid surgical resection be performed as in Japan, the five-year survival can be raised to approximately $60 \% .{ }^{1}$ Chemotherapy is the mainstay of treatment of patients with inoperable gastrointestinal cancer. Treatment of inoperable carcinoma of stomach and gastro-oesophageal junction is complex involving surgery combined with perioperative radiotherapy and/or chemotherapy. Chemotherapy achieves a significantly better overall survival rate as compressed to best supportive care alone. ${ }^{7}$ Conventional chemotherapeutic agents which are used in the inoperable carcinoma stomach are used in combination 
of three drugs [5-fluorouracil, cisplatin and epirubicin]. This is the most effective combination resulting in median survival of $8-11.2$ months. No consensus exists as for as the modalities are concerned.8,9 In spite of extensive efforts in the management and treatment of these patients, the prognosis of these patients with palliative chemotherapy remains dismal. ${ }^{9}$ Toxicity is one of the main problem associated with aggressive chemotherapy especially in elderly patients with many comorbidities. Therefore, efforts are being made to investigate molecular biology of this disease and find out molecular targets. ${ }^{10}$ The molecular targets of carcinoma of stomach and gastro-oesophageal junction are epidermal growth factor receptor (EGFR), vascular endothelial growth factor (VEGF), mammalian targets of rapamycin (mTOR), Cyclooxygenase- 2 (Cox-2) and other factors involved in the cell cycle. ${ }^{7}$ Therefore, we planned this study to evaluate the expression of HER$2 /$ neu in endoscopic biopsies of carcinoma of stomach and gastro-oesophageal junction on formalin fixed paraffin embedded blocks.

\section{MATERIALS AND METHODS}

This was an observational study. All cases of carcinoma of stomach and gastro-oesophageal junction signed out in the Department of Pathology, Government Medical College, Jammu from January 2010 to December 2016 were retrieved from surgical Pathology files and consult files. In total, 130 cases were identified over a period of six years. Haematoxylin and eosin stained sections of 5 micrometre thickness were reexamined in all cases to confirm the diagnosis. Immunohistochemistry for HER-2/neu protein was done in 85 cases. In 45 cases, the material in paraffin blocks was inadequate. Clinical features and followup data was obtained from consult files and referring surgeons.

\section{Immunohistochemistry}

Immunohistochemistry for HER-2/neu was done with the monoclonal antibodies obtained from M/s Novocastra Laboratories, Newcastle upon Tyne, UK. The LSAB kit was obtained from M/s Dako Patts, Denmark. It was done on one representative cross-sectional slide per tumour, displaying a maximum of tumour mass. We used Hofmann's criteria for immunohistochemical expression of HER-2. Hoffmann's criteria is based on the percentage of cells with membrane-like staining. ${ }^{11,12}$ Grades are classified as follows:

Grade 0: no reaction or $<10 \%$ reactivity in tumour cells; grade $1+$ : weak reactivity $>10 \%$ of the tumour cells; with reactivity only in part of the membrane; grade $2+$ : moderate reactivity in $>10 \%$ of the cells, with staining across the lateral and basolateral membrane; grade $3+$ : strong reactivity with intense staining of the lateral and basolateral membrane in $>10 \%$ of the cells. We used breast cancer, tissue HER-2 positive as external positive control. Negative control was obtained by omitting the primary antibody. We considered strong and moderate $(2+/ 3+)$ intensity staining as positive, and cases with low intensity and without reactivity as negative.

Statistical analysis was done using SPSS 10.0 windows student version \{SPSS Inc., 233 South Wacker Drive, $11^{\text {th }}$ Floor, Chicago, IL 60606-6412\}.

\section{RESULTS}

The age of patients varied from 34 to 72 years and mean age was 58.5 years. The common clinical presentation was dysplasia and regurgitation (82.4\%). Of total 85 cases, the grade of HER-2/neu expression was as follows: : 0 in 65 (76.47 $\%$ ) cases, $1+$ in $2(2.3 \%)$ cases, $2+$ (equivocal) in 4 (4.70\%) cases and $3+$ in $14(16.47 \%)$ cases.

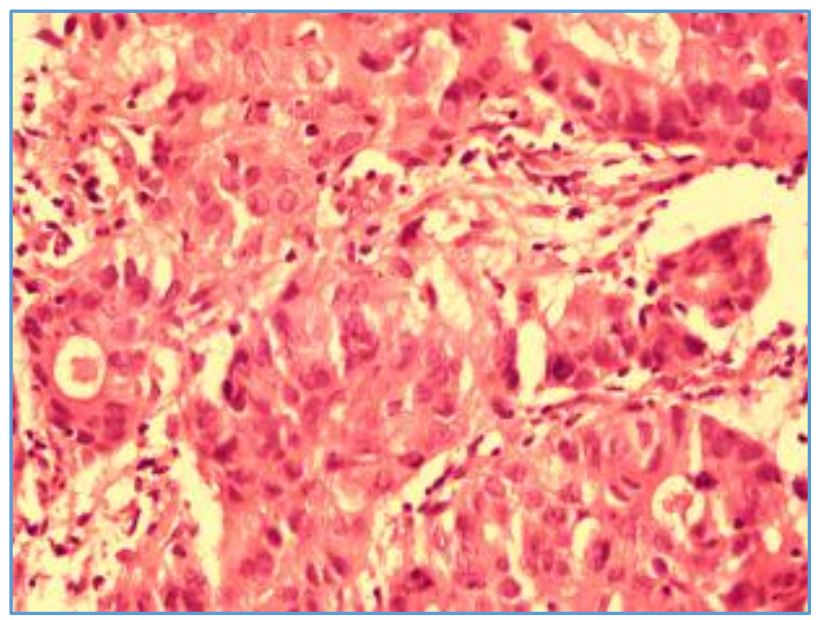

Figure 1. Microphotograph of a Case Adenocarcinoma [H\& E, 400x]

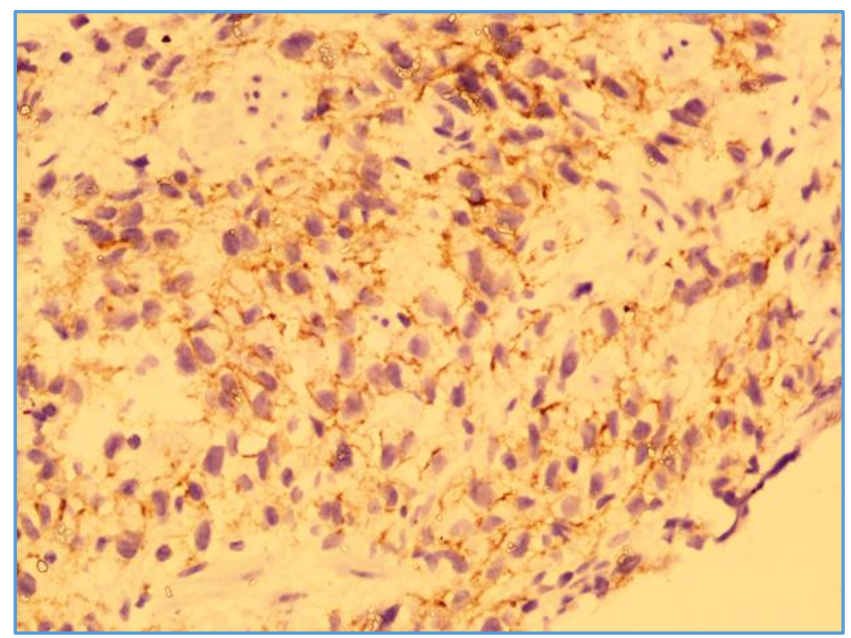

Figure 2. Immunohistochemistry for HER-2/neu in a Case of Carcinoma Stomach showing Grade 2 Positivity

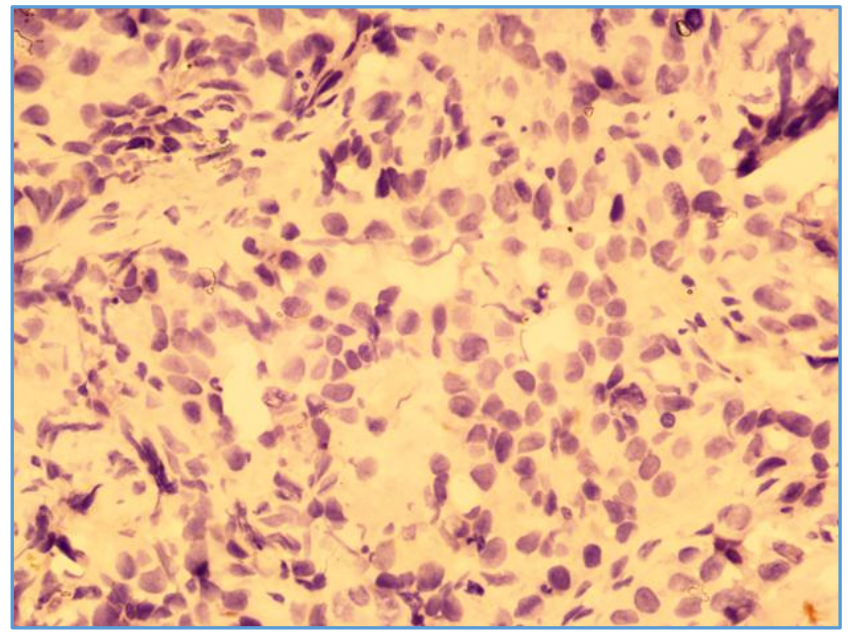

Figure 3. Immunohistochemistry in a Case of Carcinoma Stomach showing Negative Staining 


\section{DISCUSSION}

HER-2 is a receptor tyrosine kinase that belongs to Group I of 20 families of receptor tyrosine kinases. ${ }^{13}$ Other members of this group are HER-1 (erb-B1), HER-3 (erb-B3) and HER-4 (erb-B4). These tyrosine kinases are encoded by gene erb-B located on chromosome $17 q 21^{14}$ erb-B1, erb-B2, erb-B3 \& erb-B4\}. We know that receptor tyrosine kinases are transmembrane proteins with an extracellular ligand binding domain and a cytoplasmic domain. Receptor tyrosine kinase is activated transiently by binding of a specific growth factor to the extracellular domain, an event that induces homo- or heterodimerisation. ${ }^{15}$ This activation leads to downstream signalling via a number of pathways including RAS, PI3K, etc. This results in cellular proliferation and survival. Oncogenic changes in these receptors may be because of mutations, gene amplification or gene rearrangement leading to constitutive growth factor-independent tyrosine kinase activity. Hence, oncogenic tyrosine kinase receptors deliver continuous signal to the cell for cellular proliferation, ${ }^{16}$ inhibition of apoptosis ${ }^{17}$ and promote angiogenesis. ${ }^{18}$ HER-1 or EGFR is overexpressed in a subset of adenocarcinoma lung and mechanism involved is point mutation of erb-B1 gene. Molecularly targeted therapy is available for this subset of adenocarcinoma, lung. ${ }^{19}$ HER-2 is also overexpressed in many carcinomas of various other organs like breast, colon, endometrium, cervix, ovary and urinary bladder which are characteristically very aggressive. ${ }^{19}$ For the first time, HER-2 overexpression was described in carcinoma breast ${ }^{20}$ and mechanism underlying this overexpression is amplification of erb-B2 gene. Anti-HER-2 therapy is well established in treatment of carcinoma breast ${ }^{21}$ and this has assumed more significance with molecular classification of carcinoma breast.

HER-2/neu expression in our study is $21.17 \%$. Our results are very similar to those found in most American and European studies, where the prevalence rates of HER-2/neu expression are from $10 \%$ to $22.8 \% .22,23,24,10,25,26$ Most studies in Asia have reported HER-2/ neu expression prevalence of 11.7 to $15.74 \% .22,23,24,10,25,26$ In our study, the expression of HER-2/neu is $21.17 \%$. In a similar study in India by Dewan et $\mathrm{al}^{27}$ from Army Hospital Research and Referral Centre, Delhi Cantt, the prevalence of HER-2/neu expression was $17.0 \%$. So our results are almost comparable with this study. In the famous TOGA trial, ${ }^{28} \mathrm{HER}-2 /$ neu expression was $22.1 \%$ which is comparable with our study. TOGA trial was a phase III, randomised controlled multicentre study designed to test the efficacy and safety of an anti-HER-2 drug (Trastuzumab) along with conventional chemotherapy for treatment of advanced gastric cancer. This trial showed that patients with HER-2/neu expressing tumours had a survival of 16 months when their chemotherapy was combined with trastuzumab as compared to 11.5 months in patients who were given conventional chemotherapy only.

Our study has limitations that it was done on limited material of endoscopic biopsies. Another limitation is that we did not perform FISH technique to confirm HER-2/neu amplification in equivocal cases $(2+)$. In these equivocal cases when evaluated by FISH technique, the positivity rate changes. This evaluation of HER-2/neu gene amplification by FISH is important because only those cases that are grade $3+$ and $2+$ by immunohistochemistry, that are positive for FISH amplification present evidence of more benefit of adding trastuzumab to the chemotherapy regimen.28, 24, 6, 27 With advent of molecular targeted therapy, we need to determine HER-2/neu expression accurately in order to determine which patients are going to benefit from this drug.

\section{CONCLUSION}

Assessment of HER-2/neu gene amplification by FISH technique and HER-2/neu oncoprotein overexpression by immunohistochemistry should be done in all patients with gastric and gastro-oesophageal carcinoma so that these patients can be benefitted from molecularly targeted therapy i.e. Trastuzumab group of drugs. Technique of Immunohistochemistry for HER-2/neu and its interpretation in carcinoma stomach and gastro-oesophageal junction has now been standardised.

\section{REFERENCES}

[1] Kamangar F, Dores GM, Anderson WF. Patterns of cancer incidence, mortality and prevalence across five continents: defining priorities to reduce cancer disparities in different geographic regions of the world. J Clin Oncol 2006;24(14):2137-50.

[2] Comella P, Franco L, Casaretti R, et al. Emerging role of capecitabine in gastric cancer. Pharmacotherapy 2009;29(3):318-30.

[3] Dikshit RP, Mathur G, Mhatre S, et al. Epidemiological review of gastric cancer in India. Indian J Med Paediatr Oncol 2011;32(1):3-11.

[4] Sharma A, Radhakrishnan V. Gastric cancer in India. Indian J Med Paediatr Oncol 2011;32(1):12-6.

[5] Dikshit R, Gupta PC, Ramasundarahettige C, et al. Cancer mortality in India: a nationally representative survey. Lancet 2012;379(9828):1807-16.

[6] Kamangar F, Dores GM, Anderson WF. Patterns of cancer incidence, mortality and prevalence across five continents: defining priorities to reduce cancer disparities in different geographic regions of the world. J Clin Oncol 2006;24(14):2137-50.

[7] Maresch J, Schoppmann SF, Thallinger CM, et al. Her$2 /$ neu gene amplification and over-expression in stomach and esophageal adenocarcinoma: from pathology to treatment. Crit Rec Oncol Hemat 2012;82(3):310-22.

[8] King CR, Kraus MH, Aaronson SA. Amplification of a novel v-erbB-related gene in a human mammary carcinoma. Science 1985;229(4717):974-6.

[9] Yamamoto T, Ikawa S, Akiyama T, et al. Similarity of protein encoded by the human c-erb-B-2 gene to epidermal growth factor receptor. Nature 1986;319(6050):230-4.

[10] Jørgensen JT. Targeted HER2 treatment in advanced gastric cancer. Oncology 2010;78(1):26-33.

[11] He C, Bian XY, Ni XZ, et al. Correlation of human epidermal growth factor receptor 2 expression with clinicopathological characteristics and prognosis in gastric cancer. World J Gastroenterol 2013;19(14):2171-8.

[12] Hofmann M, Stoss O, Shi D, et al. Assessment of a HER2 scoring system for gastric cancer: results from a validation study. Histopathology 2008;52(7):797-805.

[13] Tschui J, Vassella E, Bandi N, et al. Morphological and molecular characteristics of HER2 amplified urothelial bladder cancer. Virchows Arch 2015;466(6):703-10. 
[14] Schechter AL, Stern DF, Vaidyanathan L, et al. The Neu oncogene: an erb-B-related gene encoding a 185,000Mr tumor antigen. Nature 1984;312(5994):513-6.

[15] Zwick E, Bange J, Ullrich A. Receptor tyrosine kinase signalling as a target for cancer intervention strategies. Endocr Relat Cancer 2001;8(3):161-73.

[16] Lenferinki AE, Busse D, Flanagan WM, et al. ErbB2/neu kinase modulates cellular p27 (Kip1) and cyclin D1 through multiple signaling pathways. Cancer Res 2001;61(17):6583-91.

[17] Yarden Y, Sliwkowski MX. Untangling the ErbB signaling network. Nat Rev Mol Cell Biol 2001;2(2):127-37.

[18] Wen XF, Yang G, Mao W, et al. HER2 signaling modulates the equilibrium between pro- and antiangiogenic factors via distinct pathways: implications for Her2 targeted antibody therapy. Oncogene 2006;25(52):6986-96.

[19] Nicholson RI, Gee JM, Harper ME. EGFR and cancer prognosis. Eur J Cancer 2001;37(Suppl 4):S9-S15.

[20] Slamon DJ, Clark GM, Wong SG, et al. Human breast cancer: correlation of relapse and survival with amplification of the HER-2/neu oncogene. Science 1987;235(4785):177-82.

[21] Tinoco G, Warsch S, Gluck S, et al. Treating breast cancer in the $21^{\text {st }}$ century: emerging biological therapies. J Cancer 2013;4(2):117-32.

[22] Barros-Silva JD, Leitao D, Afonso L, et al. Association of ERBB2 gene status with histopathological parameters and disease-specific survival in gastric carcinoma patients. Br J Cancer 2009;100(3):487-93.
[23] Gomez-Martin C, Garralda E, Echarri MJ, et al. HER2/neu testing for anti-HER2-based therapies in patients with unresectable and/or metastatic gastric cancer. J Clin Pathol 2012;65(8):751-7.

[24] Grabsch H, Sivakumar S, Gray S, et al. HER2 expression in gastric cancer: rare, heterogeneous and of no prognostic value - conclusions from 924 cases of two independent series. Cell Oncol 2010;32(1-2):57-65.

[25] Kunz PL, Mojtahed A, Fisher GA, et al. HER2 expression in gastric and gastroesophageal junction adenocarcinoma in a US population: clinicopathologic analysis with proposed approach to HER2 assessment. Appl Immunohistochem Mol Morphol 2012;20(1):1324.

[26] Ruschoff J, Dietel M, Baretton G, et al. HER2 diagnostics in gastric cancer-guideline validation and development of standardized immunohistochemical testing. Virchows Arch 2010;457(3):299-307.

[27] Dewan K, Madan R, Sengupta P, et al. Analysis of epithelial-cadherin and human epidermal growth factor receptor 2/ expression in gastric carcinoma using immunohistochemistry. IJPM 2015;58(2):154-7.

[28] Bang, YJ, Cutsem E, Feyereislova A, et al. Trastuzumab in combination with chemotherapy versus chemotherapy alone for treatment of HER2-positive advanced gastric or gastro-oesophageal junction cancer (ToGA): a phase 3, open-label, randomised controlled trial. Lancet 2010;376(9742):687-97. 